\title{
ADJUSTABLE MOUNTING JIG FOR MEAN VALUE ARTICULATOR
}

\author{
Jain Priyanka
}

Rani Durgawati Vishwavidyalaya,Jabalpur, India.

\section{ARTICLE INFORMATION:}

Article History:

Received: 03 February, 2017

Accepted in revised form: 20 May, 2017

Published:1 August, 2017

Corresponding author:

Jain Priyanka

E-mail: jainpriyanka1283@gmail.com

Keyword:

Articulator, mounting, adjustable, mean value

\section{ABSTRACT:}

An articulator is a mechanical instrument that represents the temporomandibular joints and jaws, to which maxillary and mandibular casts may be attached to simulate some or all mandibular movement. During attaching or mounting the casts, problems such as shifting of cast assembly due to compression of modelling stone or waxes. Also shifting of rubberband used for adjusting the occlusal plane during mounting. In addition, errors in transferring maxillo-mandibular relation to articulator are reproduced as errors in tooth relation and tooth movement. This article introduces a method to overcome these errors and inaccuracies during mounting in mean value articulator adjustable mounting jig.

الملخص العربي

قاعدة التثبيت القابلة للتعديل في جهاز الفكين المفصلي ذات القيمة المتوسطة جين بريانكا راني دور غاو اتي فيشو افيديالايا، جابالبور ، الهند.

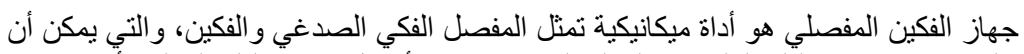

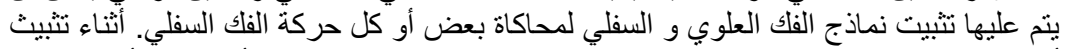

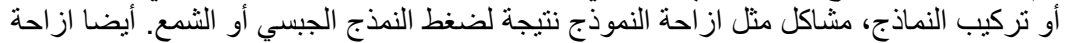

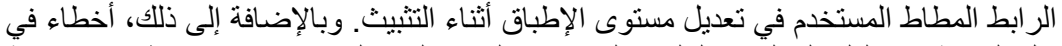

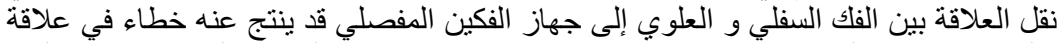

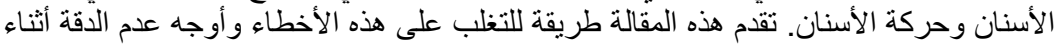

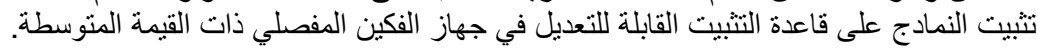

Copyright $\odot$ 2017. LDJ. This is an open access article distributed under the Creative Commons Attribution 3.0 License, which permits unrestricted use, distribution, and reproduction in any medium, provided the original work is properly cited.

Citation:Libyan Dent J 2017, 7: 267201671 -http://dx.doi.org/10.5542/LDJ.v7i0.267201671 


\section{INTRODUCTION}

An articulator is a mechanical instrument that represents the temporomandibular joints and jaws, to which maxillary and mandibular casts may be attached to simulate some or all mandibular movement. ${ }^{1}$ The primary function of the articulator is to act as patient in the absence of patient. It is often said that the patients mouth is the best articulator yet mechanical articulators do have many advantages and allows to fabricate a prostheses, that will be physiologically and psychologically successful. ${ }^{2}$

At the international prosthodontic workshop on complete denture occlusion, at the university of Michigan in 1972, an articulator classification was developed based on the instrument function. A three point articulator was classified under a Class IIA instrument that permits eccentric motion based on average or arbitrary values. ${ }^{3}$ Three point articulators were used and are being used for demonstration of teeth arrangement in preclinics as well as in clinics. It is essential that the casts representing the patient's mandible and maxillae be oriented in the articulator similarly to the manner in which the jaws of the patient are oriented to one another. ${ }^{4}$ Errors in transferring maxillo-mandibular relation to articulator are reproduced as errors in tooth relation and tooth movement. No instrument is effective unless it accurately accepts the records. ${ }^{5}$ During transfer of maxilla-mandibular relation to the mean value articulator clay/waxes used to support the cast assembly. The problems encountered during mounting are shifting of cast assembly due to sagging/ compression of modelling clay/waxes and shifting of thread/rubberband used for adjusting the occlusal plane during mounting. To overcome these errors and inaccuracies during mounting in mean value articulator adjustable mounting jig is designed.

\section{PARTS OF ADJUSTABLE MOUNTING JIG}

1. Articulating plate-it is made up of stainless steel, triangular shaped, used to attach entire jig to lower member of mean value articulator.

2. Mounting plate-it is made up of aluminium, due to its light weight and durability, triangular shaped with central groove for checking midline in place of incisal pin/to match anterior reference point. It is used to hold the upper cast assembly (edentulous cast with wax rim/partially edentulous cast/completely edentulous cast) to be mounted according to plane of orientation with the help of carding/sticky wax. It is extending posteriorly up til horizontal bar of articulator to match posterior reference points.
3. Central adjusting cylinder- it is made up of stainless steel central screw and screw holder. Its central screw is attached with upper mounting plate with cylindrical fixture to allow its controlled ball and socket joint movements for antero-posterior as well as lateral movements of mounting plate to adjust according to plane of orientation. Screw holder is fixed to lower articulating plate and allows central screw to be moved up and down according to adjustment required; also its having tightening screw at one side to fix upper and lower parts of jig at required position.

4. Fixture screw used to fix entire jig assembly to lower part of mean value articulator. It is provided with rubber stopper to accept all sizes of screw holes.

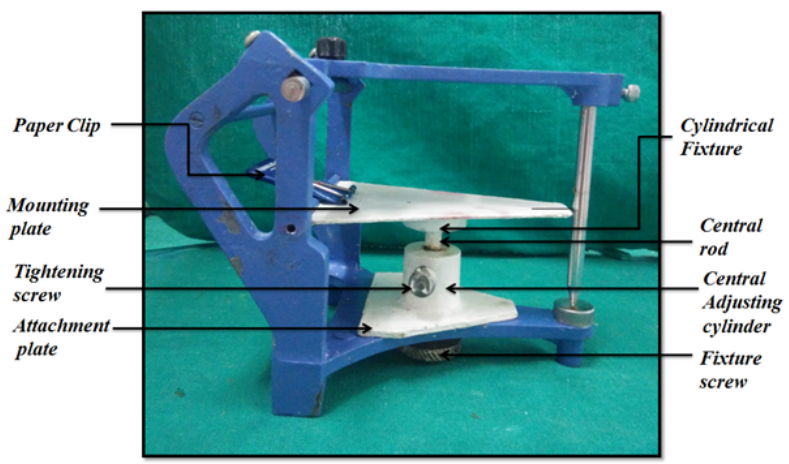

Fig 1: Parts of mounting jig.

\section{ATTACHING THE JIG TO ARTICULATOR AND MOUNTING OF OCCLUSAL RIMS}

1. The mounting jig is attached to the articulator at its lower assembly with the help of fixture screw to the hole with which lower mounting ring is attached.

2. Onto the mounting plate the maxillary occlusal rim is held securely by carding or sticky wax (Fig 2).

3. The mounting plate is adjusted according to the plane of occlusion which should coincide with following reference points.

a) Anterior reference point is incisal pin which should coincide with midline of maxillary rim.

b) Posterior reference points coincide with intercondylar distance (simulated by horizontal bar of the articulator).

4. After adjustment plaster is poured onto the base of the maxillary cast and mounting is performed thereafter (Fig 3).

\section{CONCLUSION}

Adjustable mounting jig can be used for all types of standard mean value articulators. It eliminates use of clay, waxes and thread that causes manual discrepancy 
during conventional mounting procedure. Besides the mounting edentulous cast, jig can also be practised for dentulous cast mounting in removable and fixed partial denture cases. The simplicity of design and handling saves time and allows preclinical as well as clinical mounting procedure at undergraduate and postgraduate level. However, cases with altered occlusion (such as supra occlusion/collapsed bite) may pose difficulty in aligning the cast.

The late Carl $O$ Boucher summed up the articulator by stating "it must be recognized that the person operating the instrument is more important than the instrument. If dentist understands articulators and their deficiencies, they can compensate for their inherent

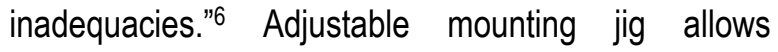
accurate mounting of maxillary cast in mean value articulator making an easy, time saving procedure. Apart from certain limitations which should be overcome to advent its modification, it is the instrument of choice for quick lab mounting.

\section{REFERENCES}

1. The Academy of Prosthodontics Glossary of prosthodontic terms 8th edn. J Prosthet Dent. 2005;94:10-92.

2. Zarb GA, Bolender CL, Hickey JC. Boucher's prosthodontic treatment for edentulous patients. 9th Edition. St. Louis:C.V, Mosby,1985.pp.306-23.

3. Lang BR, Kelsey (eds): International prosthodontic workshop on complete denture occlusion. Ann arbor, University of Michigan School of Dentistry, 1973, pp 89-96.

4. Winkler S. Essentials of complete denture prosthodontics, 2nd ed. Ishiyaku Euro America Publishers, 1996, pp 123-284.

5. Heartwell CM, Rahn AO. Syllabus of complete dentures, 4th ed. Lea and Febiger, Philadelphia, 1992, pp 265-356.

6. Boucher $\mathrm{CO}$. Complete denture prosthodonticsthe state of the art. J Prosthet Dent 1975;34:372-83.

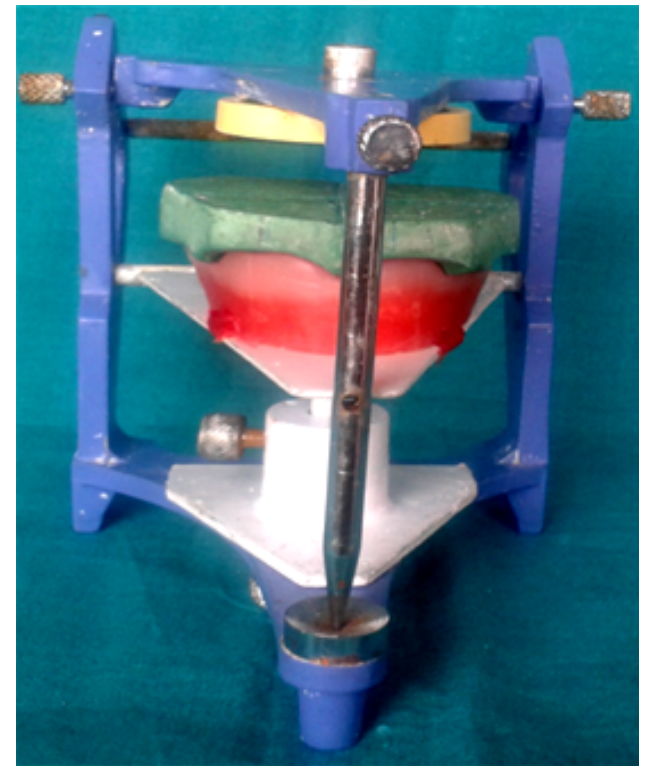

Fig 2: Maxillary cast secured to jig.

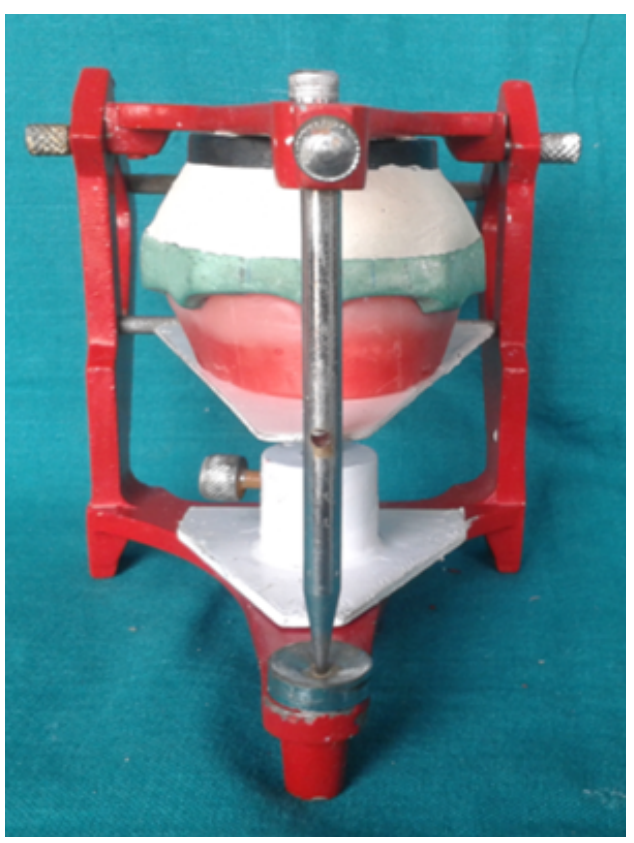

Fig 3: Mounted Maxillary cast. 